PAPER PUBLISHED IN INTERNATIONAL JOURNAL OF OPERATIONS AND PRODUCTION MANAGEMENT

Roldán Bravo, M.I., Ruiz Moreno, A. and Lloréns Montes, F.J. (2018). Examining desorptive capacity in supply chains: the role of organizational ambidexterity, International Journal of Operations \& Production Management 38(4), 534-553.

DOI: 10.1108/IJOPM-12-2016-0751 


\section{Examining Desorptive Capacity in Supply Chains: The role of Organizational}

\section{Ambidexterity}

\section{Abstract}

Purpose - The purpose of this paper is to explain how an organization's desorptive capacity relative to its supply network enhances that organization's supply chain competence and the contingent role of the balanced and combined dimensions of ambidexterity in this relationship.

Design/methodology/approach - Empirical results are provided through analysis of data from a survey conducted on a sample of 270 European firms. Hierarchical regression analysis is used to test the hypotheses.

Findings - The results confirm both the positive and significant relationship between an organization's desorptive capacity and that organization's supply chain competence, and the key moderating role of organizational ambidexterity, especially in its combined dimension, on the above-mentioned relationship.

Practical implications- Our study suggests that desorptive capacity is key to the contribution an organization makes to its supply chain's competitiveness. We also provide practitioners with better understanding of the extent to which they should attempt to balance exploration and exploitation or/and to maximize both simultaneously when seeking greater benefit from desorptive capacity.

Originality/value- This study extends desorptive capacity research to supply chain management and responds to calls in the literature on desorptive capacity to study the benefits of this capacity in greater depth and to determine the role organizational ambidexterity plays in the success of desorptive capacity. By analyzing the independent effects of the combined and balanced dimension of ambidexterity, we advance the conceptual and operational understanding of the role of ambidexterity needed in the 
literature.

Keywords Desorptive capacity, Supply chain competence, Combined ambidexterity, Balanced ambidexterity, Supply network.

Paper type Research paper

\section{Introduction}

Recent literature complements the traditional concept of absorptive capacity with the term desorptive capacity (Lichtenthaler and Lichtenthaler, 2009, 2010), which highlights the importance of external knowledge exploitation or outward knowledge transfer. A firm that exploits its knowledge by transferring it beyond the organization's boundaries can generate value through creation or exploitation of complementary resources (Teece, 1986). In this case, value creation does not rely on the organization's mere possession of valuable knowledge assets, but on its capacity to desorb its knowledge in order to exploit that knowledge effectively. The cases of IBM and Open Telecom platforms illustrate the importance and potential benefits of desorptive capacity in an organization, for example, the materialization of learning effects.

Despite the importance of desorptive capacity for firms, research has paid it relatively little attention (Florén and Frishammar, 2012; Jia and Lamming, 2013; Scherrer-Rathje et al., 2014; $\mathrm{Hu}$ et al., 2015; Meinlschmid et al., 2016). We address recent calls in the literature to explore the construct of desorptive capacity and its impact on performance and competitiveness in greater depth. Under current economic conditions, achieving sustainable competitive advantage requires that researchers and practitioners adopt a macro-focus on the entire supply chain (Lummus et al., 2008 in Green et al., 2014), as competition has evolved to supply chain level. It is not clear, however, why some companies contribute greatly to their supply chain's 
competitiveness by managing the supply chain more competently. In this context, our study attempts to fill this gap by analyzing how knowledge desorption mechanisms actually support an organization's supply chain competence.

Desorptive capacity can be partner-specific, as is absorptive capacity, and varies based on the source of the external knowledge to which it relates (Dyer and Singh, 1998; Wagner, 2012). Our focus - how desorptive capacity can enhance supply chain management — has led us to study this capacity as it relates to the organization's supply network. Following Narasimhan and Narayanan (2013), we understand supply network as the possible network of upstream suppliers in the firm's value system directly or indirectly (p. 28). We presume that desorptive capacity enables a knowledge transfer context in which the buyer acts as a teacher firm and the supply network as a student firm.

Recent literature relates successful desorptive capacity to the coexistence of exploratory and exploitative learning styles -organizational ambidexterity-, since "those who understand, teach" (Schulze et al., 2014). The literature shows no clear understanding, however, of how organizational ambidexterity, influences the organization's ability to obtain benefits from desorptive capacity. Recent research recognizes this gap and calls for further study (Hu et al., 2015). The assumption under ambidexterity is that firms capable of managing both exploratory and exploitative activities will be more successful (Tushman and O'Reilly, 1996; Rothaermel and Alexandre, 2009; Tamayo Torres et al., 2014; Wei et al., 2014). In particular, the field of supply chain and operations management has recently recognized the importance of "getting the best of both worlds" (Patel et al., 2012; Blome et al., 2013). Our investigation follows this line of study. Using the concept of simultaneous pursuit of exploratory and exploitative learning, we theorize its contingent role in the relationship 
between desorptive capacity and supply chain competence. This moderating role has been studied by analyzing organizational ambidexterity in its two dimensions, balanced and combined ambidexterity, which have been used indiscriminately in the literature due to lack of researchers' consensus on the construct. In fact, some studies interpret ambidexterity as the balance between exploration and exploitation; others, as the maximization of both; and yet others, as a blend of the two. The study by Cao et al. (2009) adopts the latter approach and is the first analysis to clarify theoretically the construct ambidexterity by separating it into the two dimensions we apply here. By considering the independent effects of balanced and combined ambidexterity, we advance the conceptual and operational understanding of the role of ambidexterity needed in the literature. We thus provide practitioners with better understanding of the extent to which they should attempt to balance exploration and exploitation or/ and to maximize both simultaneously when seeking greater benefit from desorptive capacity.

We thus summarize the general purpose of this study as to analyze how an organization's desorptive capacity relative to its supply network improves that organization's competence in managing its supply chain. More specifically, this study has three objectives. The first consists of analyzing the direct relationship between desorptive capacity and supply chain competence. The second is to analyze the moderating character of the buyer's combined ambidexterity in this relationship. The third is to examine the moderating character of the buyer's balanced ambidexterity in the above-mentioned relationship.

To fulfill these objectives, the study is structured as follows. The next section conceptualizes desorptive capacity and supply chain competence, and develops the hypotheses. We then discuss the methodology, including data collection, measurement instruments, and control variables. Subsequently, we present the empirical results, 
followed by discussion of the findings. Finally, we develop the theoretical and managerial implications, research limitations, and future lines of research.

\section{Theoretical background and hypotheses}

\subsection{Desorptive capacity}

Desorptive capacity is a knowledge capacity defined as a "firm's ability to externally exploit knowledge" (Lichtenthaler and Lichtenthaler, 2009, p. 1322). As outward knowledge transfer (Müller-Seitz, 2012), desorptive capacity is the inverse of absorptive capacity in an organization. It is present when the organization can identify the opportunities for exploiting its knowledge based on monetary and strategic motives, and transfer this knowledge effectively (Lichtenthaler and Lichtenthaler, 2009).

Prior literature links the effectiveness and efficiency of knowledge transfer to the disseminative capacity of knowledge senders, that is, the ability to transfer the knowledge needed (Tang et al., 2010). Firms must disseminate their knowledge across their organization's boundaries to maximize its value. This ability minimizes misunderstanding and duplication of knowledge transfer, helping to transfer knowledge faster beyond the organization. Such interactivity will lead the network as a whole to refresh its knowledge at a faster pace.

As the study by Yang et al. (2014) explains, firms must simultaneously facilitate knowledge exchange and protect their core proprietary knowledge. Although the literature has viewed these two activities as contradictory, effective knowledge transfer and knowledge protection can be achieved by enhancing the organization's desorptive capacity. Desorptive capacity has recently been highlighted as an important capacity enabling flow of knowledge beyond the organization's boundaries by permitting 
management and transfer of the organization's external knowledge (Vanhaverbeke et al., 2007; Lichtenthaler and Lichtenthaler, 2010; Martín de Castro, 2015). Disseminative capacity is included in the broader concept of desorptive capacity, which is conceived as a dynamic capability composed of "sensing," "seizing," and "transforming" capacities (Teece, 2007). The authors who introduced this construct propose two main phases of desorptive capacity: identification of knowledge transfer opportunities and knowledge transfer (Ziegler et al., 2013).

Development of this capability can bring strategic and non-economic benefits, such as access to external knowledge or establishment of industry standards (Grindley and Teece, 1997; Arora et al., 2001), benefits that can reinforce an organization's competence to manage its supply chain, as our study proposes.

\subsection{Supply Chain Competence}

The supply chain's competitive position and quality are strengthened by each organization's competence to manage the chain. This competence is constructed as practices are adopted and problems solved in managing the supply chain (Chow et al., 2008); it is the result of the organization's continuous learning (Spekman et al., 2002) and permits the organization to attend to demands under any circumstances - that is, to be more flexible and to meet the changing demands of the market it serves, as well as to achieve supply chain excellence in its area of operation (Kuei et al., 2005).

Supply chain competence has been defined by Chow et al. $(2008$, p. 667) as "a portfolio of organizational, managerial, technical and strategic capabilities and skills developed by enterprises over time," composed of quality and service issues, and operation and distribution issues. For Fisher et al. (2000), it is essential to develop the 
following capacities: foresight, inventory planning, speed of the supply chain, and precision of data. Bowersox et al. (2000) define this competence as a supply chain's ability to attend customer demands with low cost and high-quality products and services. For Green et al. (2014), supply chain competence reflects supply chain performance.

The key characteristic of this competence has been shown in studies such as Hsu et al. (2011) and Heide et al. (2008), who also identify a gap in the literature on this construct. They argue the need to study supply chain competence in greater depth due to its key role in maintaining competitive advantage over time, determining the distribution, quality, and service delivered to the customer, and, ultimately, achieving excellence in supply chain operations. The literature (Green et al., 2014) also indicates that it is important to study this construct because competition has shifted and now occurs among supply chains rather than among firms.

Studies by Chow et al. (2008), Kannan and Tan (2005), and Kuei et al. (2005) demonstrate the positive impact of the capacities inherent in supply chain competence on performance. An organization improves its performance through capacities that are a source of competitive advantage and that thus contribute to improving performance (Tamayo Torres et al., 2011). Excellence in supply chain management permits customer satisfaction and achievement of competitive advantage if one performs better than the competition in this respect (Flint et al., 2008).

As Green et al. (2014) show, optimization at supply chain level through improved supply chain competence leads to improved organizational performance for each participating supply chain partner. 


\subsection{Effects of desorptive capacity on supply chain competence}

An organization that has the capacity to transfer knowledge effectively to other organizations — desorptive capacity—enjoys a competitive advantage over organizations without this capacity (Lawson and Potter, 2012; Najafi Tavani et al., 2013). When firms exchange knowledge, effectively avoiding risks (Larsson et al., 1998), they must adopt a strategy with moderate transparency and receptivity and thus, develop their desorptive capacity. Ritala et al. (2015) highlight the organization's need to transfer knowledge to access to external knowledge. Transferring knowledge demands teaching (Winter, 1987), and an organization that teaches is motivated to accept new knowledge. IBM exemplifies the benefits of outward knowledge transfer (Chesbrough, 2006).

Possessing desorptive capacity can bring the organization non-economic benefits, such as access to external knowledge, entry in new markets, and establishment of the standards of the industry in which it operates, as well as greater knowledge of the markets it does or may potentially serve (Lichtenthaler and Lichtenthaler, 2010; Hu et al., 2015) and greater likelihood of understanding others' needs and thus of responding accordingly (Yang et al., 2014). Liu et al. (2012) argue that knowledge exchange helps organizations to understand their products and processes, the competition they face, and markets, enabling improvement of their problem-solving capacity and their foresight and coordination of production and delivery activities, inventory-related activities, etc. (Paulraj et al., 2008; Wu et al., 2014).

In the case studied here, we propose that the buyer organization's capacity to transfer knowledge to its supply network strengthens improvement of supply chain competence, since this capacity can bring access to relevant external knowledge, among other benefits. Malhotra et al. (2005) explain that accessing knowledge from external 
partners can lead an organization to adapt better to its environment and thus to enhance its existing competences.

When a firm enhances efficiency of knowledge exchange-by developing desorptive capacity - it may be able to internalize the knowledge possessed by the supply network (Yang et al., 2014). Developing supply chain competence through knowledge sharing is a source of competitive advantage, since desorptive capacity can be extremely hard for others to imitate. We propose that desorptive capacity enhances an organization's understanding of the social and organizational contexts in which knowledge is created, processed, shared, and applied, enabling it to better perceive, understand, and make sense of new knowledge from the supply network by applying this knowledge to commercial needs in a more efficient and effective way reflected in improved supply chain competence.

Firms' competitiveness can be linked to their success in knowledge sharing (Mu et al., 2010) and thus to development of desorptive capacity. Organizational strategies, like developing desorptive capacity, that support supply chain strategies should strengthen the supply chain's competitive position (Green et al., 2014).

We thus propose verifying the following hypothesis:

H1. An organization's desorptive capacity is positively and significantly related to its supply chain competence. 


\subsection{Moderating variables}

2.4.1. Moderating effect of balanced and combined ambidexterity. Current research proposes that accumulation of desorptive capacity requires exploitation and exploration in order to search for and discover potential opportunities for the firm's knowledge transfer (Hu et al., 2015).

Exploitation involves "learning based on certainty," whereas exploration is "learning based on probability" (Azadegan and Doley, 2010, p. 490). March (1991, p. 71) defines exploration as "search, variation, risk-taking, experimentation, play, flexibility, discovery, and innovation," and exploitation as "refinement, choice, production, efficiency, selection, implementation, and execution."

The literature has considered the different learning styles of exploitation and exploration as conflicting rather than complementary, but both activities are necessary to achieve desorptive capacity and, ultimately, the organization's survival and maintenance of competitive advantage through efficiency and creativity (March, 1991; Levinthal and March, 1993). This reasoning supports the benefits of having exploration and exploitation coexist in the organization-organizational ambidexterity. Our study proposes that joint pursuit of exploration and exploitation provides fertile ground for more effective achievement of the performance benefits emanating from desorptive capacity.

Organizational ambidexterity is defined as the organization's ability simultaneously to pursue both explorative and exploitative activities (O'Reilly and Tushman, 2004 in Junni et al., 2013). The general agreement in this literature is that an ambidextrous firm can both exploit existing competences and explore new opportunities. Thus, organizational ambidexterity enables a firm to enhance its performance and competitiveness (Cao et al., 2009). There is no consensus, however, 
regarding the extent to which ambidexterity can be conceived as a balance of exploration or exploitation (balanced ambidexterity) or as a simultaneous maximization of both (combined ambidexterity). He and Wong (2004), among others, highlight the two differing interpretations of ambidexterity in the literature, focusing especially on the different measurements used to operationalize ambidexterity. The most notable differences in the conceptualizations of organizational ambidexterity concern whether it involves combination of high levels of both exploration and exploitation or an optimal point on a continuum (Junni et al., 2013).

From the balanced organizational ambidexterity perspective, firms must ensure that they have the optimal mix of exploration and exploitation to succeed in the short and long term (March, 1991). Balanced ambidexterity reduces the risks of excess exploration or exploitation in an organization's performance, granting more structured control of the risks of obsolescence or failure to appropriate (Levinthal and March, 1993; March, 1991 in Cao et al., 2009). When a firm has desorptive capacity and enjoys high balanced ambidexterity, we reason that existing knowledge and resources and proper knowledge transfer can be used to enhance existing competences, such as supply chain competence. Simultaneously, new knowledge and resources accessed can, to a greater extent, enhance and be integrated into supply chain competence. Balanced ambidexterity can help to reduce fear of the knowledge leakage involved in knowledge transfer activities, reinforcing the positive influence of developing desorptive capacity in an organization.

Combined ambidexterity considers exploration and exploitation as independent activities that can and should be maximized to achieve a high level of organizational ambidexterity (Cao et al., 2009; Simsek et al., 2009 in Junni et al., 2013).

We posit that greater advantages of desorptive capacity can be derived from 
maintaining high levels of exploration and exploitation. Exploratory and exploitative processes support both each other and desorptive capacity for several reasons. A high degree of exploitative activities can improve an organization's exploration activities. Through repeated use of existing knowledge and resources, management deepens understanding of its functionality, achieving greater ability for knowledge transfer and thus enhancing the possibility of gaining benefits from desorptive capacity. As Cao et al. (2009) reason, a high degree of exploitative effort can lead to existing knowledge reconfigurations and better recognition and assimilation of new external knowledge and resources.

Successful exploration can enhance the influence of an organization's desorptive capacity on its supply chain competence. Accessing and integrating outside knowledge can lead to application of the organization's efficient routines and processes on a greater scale, and better recognition of knowledge transfer opportunities.

Firms should thus achieve high levels of both activities simultaneously to leverage their complementarities, thereby reinforcing the benefits of desorptive capacity (Gibson and Birkinshaw, 2004; Gupta et al., 2006; Simsek et al., 2009).

Organizations should appropriately and dynamically balance their levels of exploration and exploitation, and simultaneously align exploitation and exploration to achieve their complementary effects (Chen, 2002; Smith and Lewis, 2011) in reinforcing the advantages of organizational desorptive capacity. Organizations that teach and achieve ambidexterity can capture and absorb relevant information at any moment in a more precise way, a capability that enables them to anticipate market tendencies and discard routines that are no longer operational. In responding flexibly to demand and fulfilling customers' needs creatively (Lubatkin et al., 2006), firms improve quality while reducing costs (Patel et al., 2012). 
Based on the foregoing, we propose verifying the following hypothesis:

H2. Organizational ambidexterity positively and significantly moderates the relationship between desorptive capacity and supply chain competence.

$H 2 a$. The balanced dimension of ambidexterity positively and significantly moderates the relationship between desorptive capacity and supply chain competence.

$H 2 b$. The combined dimension of ambidexterity positively and significantly moderates the relationship between desorptive capacity and supply chain competence.

Figure 1 summarizes our research model and hypotheses.

Figure 1

Summary of Hypotheses

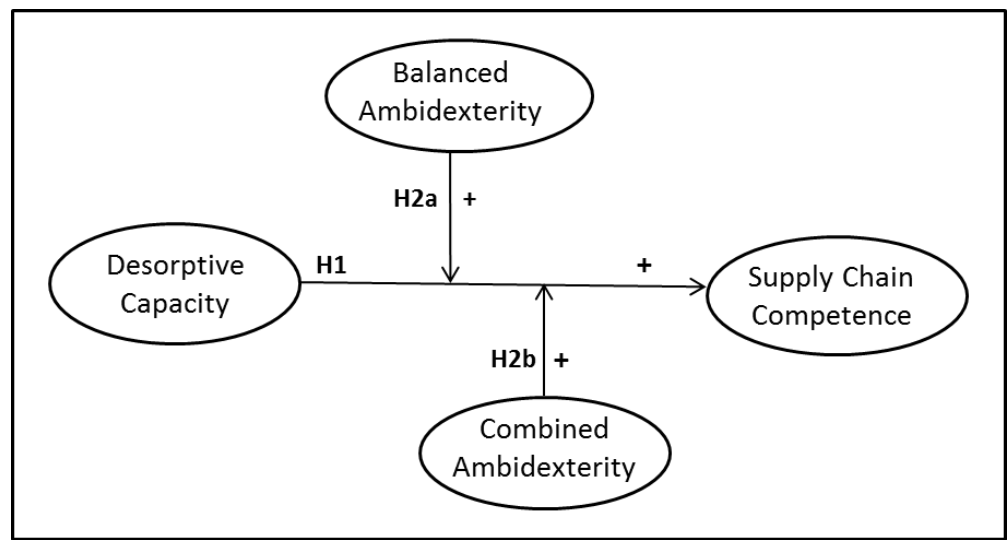




\section{Methodology}

\subsection{Sampling and data collection}

Potential respondents were identified from the Iberian Balance Sheet Analysis System (SABI) databases. A sample of 2,000 manufacturing and service firms was chosen at random. In all cases considered valid, the informants were logistics/purchasing executives. The study used a computer-assisted telephone interview survey method and electronic surveys. The responses were collected from June to October 2013. We received 290 responses, for a response rate of $14.5 \%$. Accounting for missing responses, we obtained a final sample of 270 usable surveys, achieving a final response rate of 13.5\%. Table I provides an overview of our sample.

\section{Insert Table I about here}

\subsection{Measures}

Theoretical constructs were adapted from previously established and tested scales. Initially, a pre-test was used to prepare the survey for distribution to a large sample. The scale was carefully examined by selected practitioners and academicians in the field for translation, wording, structure, and content.

Desorptive capacity. We measured this construct using the three items validated in the study by Roldán Bravo et al. (2016), to which the survey respondents were to indicate their degree of agreement or disagreement with the statements proposed on a Likert scale from 1 to $7(1=$ totally disagree to $7=$ totally agree $)$. Desorptive capacity enables organizations to identify the opportunities for exploiting their knowledge and transferring this knowledge effectively (Lichtenthaler and Lichtenthaler, 2009). Item 1 
expresses the organization's ability to identify relevant knowledge to transfer to its supply network. Items 2 and 3 cover the effectiveness of knowledge transfer by expressing knowledge in a way appropriate to the organization and providing sufficient support for the knowledge transfer. Factor loadings ranged from 0.79 to 0.94 . The scale's validity was confirmed with a Cronbach's alpha of 0.925 .

Supply chain competence. The measurement items for supply chain competence were adapted from the instrument developed by Chow et al. (2008), which contains eight items. One item was deleted due to factor loadings of less than 0.5 (Hair et al., 2010). Supply chain competence was measured as a variable comprised of quality and service issues, as well as operations and distribution issues. A seven-point Likert scale $(1=$ totally disagree to $7=$ totally agree $)$ was developed. Factor loadings ranged from 0.71 to 0.82 . The Cronbach's alpha of 0.916 indicates the scale's reliability.

Exploration and exploitation. Our measures of balanced and combined ambidexterity stem from measures of exploration and exploitation. Exploration and exploitation were adapted from the study by Azadegan and Doley (2010) for the purpose of our study. Purchasing managers were asked to show their agreement or disagreement with three statements proposed for exploration and another three for exploitation (one item for exploitation was deleted due to factor loadings of less than $0.5)$ on a Likert scale from 1 to 7 (1=totally disagree; 7=totally agree). While exploratory learning shows predominant use of new ideas and procedures in an organization, causing its income from sales to proceed primarily from new products, exploitative learning emphasizes improvement in efficiency, existing technologies, and continuous improvement of the organization's procedures, policies, and rules. Factor 
loadings for exploration ranged from 0.71 to 0.79 , and the Cronbach's alpha of 0.781 indicates the scale's reliability. In the case of exploitation, factor loadings ranged from 0.8 to 0.83 and the Cronbach's alpha of 0.807 also indicates the scale's reliability.

Balanced and combined ambidexterity. The balanced dimension of ambidexterity entails the balance of the relative magnitudes of exploration and exploitation. We have operationalized this dimension following the procedure of $\mathrm{He}$ and Wong (2004), also followed in other studies (e.g., Cao et al., 2009), using the absolute difference between exploration and exploitation and reversing it by subtracting the difference score from 7 so that a higher value indicates greater balanced dimension. The combined dimension of ambidexterity concerns the combination magnitude of the two learning styles. We operationalized this dimension by multiplying both magnitudes following the procedure of previous studies (He and Wong, 2004; Gibson and Birkinshaw, 2004; Cao et al., 2009). To avoid potential multicollinearity, we meancentered the exploration and exploitation scales before obtaining their product.

Control variables. The literature shows the importance of considering the relationship between organizational size and organizational ambidexterity (Andriopoulos and Lewis, 2009). Our study considers firm size as a control variable, since managing exploration-exploitation tensions could be vital in larger firms (Lubatkin et al., 2006). Consistent with research conventions, we used logarithmic transformations for number of employees. As a contextual factor, we considered the sector to which the organization belongs (secondary or service). Finally, we controlled for the potential independent effects of exploration and exploitation on supply chain competence, as have previous studies (among others, He and Wong, 2004; Cao et al., 2009). 


\subsection{Non-response bias and common method variance.}

Following Armstrong and Overton (1977), we assessed the presence of non-response bias in the sample, comparing early and late groups of respondents. The results of comparing the two groups (early respondents $=169$; late respondents $=101$ ) indicate no systematic non-response bias in the survey data $(p=0.05)$.

Since we had one respondent per firm, common method variance could be a concern. We therefore performed methodological tests, specifically, Harman's single factor test, widely used in the literature (Podsakoff et al., 2003). We loaded all variables in the exploratory factor analysis, constraining the number of factors to 1 . As the first component accounts for less than $50 \%$ of all variables, common method variance is not a serious problem in our sample. We also employed exploratory factor analysis for the first-order level of constructs, which revealed 4 first-order factors with eigenvalues $>1.0$, accounting for $72.641 \%$ of the variance. Considering that a single factor did not emerge and given that the first factor did not account for the majority of the variance, these results reinforce those of the previous test.

\subsection{Reliability and validity.}

We assessed construct validity with a confirmatory factor analysis. All factor loadings are significant $(\mathrm{t}>1.96 ; p<0.05)$ - greater than 0.5 - and the value for individual reliability is above $50 \%$ for all but two items (one used to assess supply chain competence and the other to assess exploitation), which were eliminated. The model fit indices (normed $\chi^{2}=3.09, \mathrm{CFI}=0.93, \mathrm{NNFI}=0.91, \mathrm{RMSEA}=0.08$ ) indicate that the model fits the data well.

Following Fornell and Larcker (1981), we used average variance extracted to evaluate convergent validity. The average variance extracted for desorptive capacity (0.8), supply chain competence (0.58), exploration (0.54), and exploitation (0.67) 
exceed the criterion of 0.5 . The composite reliabilities for desorptive capacity (0.92), supply chain competence (0.92), exploration (0.78), and exploitation (0.8) exceed the criterion of 0.7. Discriminant validity is assumed to exist if the squared average variance extracted for each construct exceeds its shared variance (correlation). This condition was found in all combinations of paired constructs, providing evidence of discriminant validity for all scales. Table II shows the descriptive statistics, correlations among constructs, and squared average variance extracted for each construct.

\section{Insert Table II about here}

\section{Results}

To contrast the hypotheses, we used hierarchical regression analysis (Table III). In a preliminary stage, we performed regression analysis among the dependent and control variables. We then performed regression analysis among the dependent and moderating variables. The next phase included the independent variable. Finally, we added two terms that represented the interactions between the independent variable and each of the moderators. To avoid problems of multicollinearity, we centered the interaction terms relative to the mean before calculating their product. The tolerance value and variance inflation factor of the independent variables were within the accepted limits for rejecting the presence of multicollinearity.

The results from Model 3 in Table III show that the coefficient for desorptive capacity is positive and significant. This result suggests, as hypothesized, that desorptive capacity positively impacts supply chain competence (H1: $\beta=0.445$, $\mathrm{p}<0.001$ ), providing support for Hypothesis 1 . As shown by Model 4 in Table III, the

estimated coefficient for the interaction terms between desorptive capacity and the balanced and combined dimensions of ambidexterity are significant and positive. These 
results suggest that the balanced and combined dimensions of ambidexterity significantly moderate the influence of desorptive capacity on supply chain competence. In the presence of organizational ambidexterity, the positive relationship between desorptive capacity and supply chain competence becomes stronger, especially for the combined dimension, supporting Hypothesis $2 \mathrm{a}(\mathrm{H} 2 \mathrm{a}: \beta=0.10, \mathrm{p}=0.055)$ and Hypothesis $2 b(H 2 b: \beta=0.13, p=0.013)$.

\section{Insert Table III about here}

\section{Discussion, implications, limitations and future research directions.}

We hypothesized a study model consisting of the relationship between desorptive capacity and supply chain competence. Potential moderator effects of the balanced and combined dimensions of organizational ambidexterity were theorized.

Close examination of this model with empirical data supports the applicability of desorptive capacity in a supply chain context. Specifically, we addressed desorptive capacity from a partner-specific perspective and demonstrated the direct impact of the organization's capacity as related to its supply network on its competence to manage its supply chain — supply chain competence. These results support accepted assumptions of the desorptive and disseminative capacity literature in that knowledge transfer can bring economic and non-economic benefits for the sender organization (Tranekjer and Knudsen, 2012). This finding extends earlier results by Simonin (1997), Madhok and Talman (1998), Hardy et al. (2003), and the recent study by Ryo and Kim (2015), which hold that sharing knowledge in a network setting can bring operational performance for organizations as a result of fitting or adapting their inter- firm processes. Our finding reinforces the value of desorptive capacity as a dynamic capability for sustained value creation and supply-chain competitive advantage. 
We further identified the moderating role of the balanced and combined dimensions of ambidexterity on the relationship between desorptive capacity and supply chain competence as significant. Our results confirm that the coexistence and combination of exploration and exploitation processes have strong effects that reinforce an organization's desorptive capacity, as the recent study by Hu et al. (2015) recognizes. Thus, excessive focus on one learning process can have negative consequences, while balanced or combined development improves desorptive capacity performance in the context of our study. This study shows that ambidexterity serves as a mechanism to help firms to leverage their capacity to desorb knowledge in a supply chain context.

Given the ambiguity surrounding conceptualization of organizational ambidexterity, we follow the recommendation of Cao et al. (2009) and consider the independent effects of the two distinct dimensions of ambidexterity previously used in the literature. Analyzing our results in greater detail, we observe that firms should balance levels of exploration and exploitation appropriately to avoid the "risks of failure to appropriate" or "the risks of obsolescence" (Levinthal and March, 1993; He and Wong, 2004; Cao et al., 2009), which inhibit the potential of the organization's desorptive capacity. Our results show, however, that the effort to combine a great magnitude of exploration and exploitation is even more crucial. This result supports the prediction of the paradox view (Wei et al., 2014) - the compatibility and complementarity of exploratory and exploitative learning. Finally, this finding encourages and approves firms that wish to benefit from their desorptive capacity but are faced with the option of balancing exploration and exploitation activities or combining high levels of both. 


\subsection{Theoretical implications}

This study makes three major contributions to the existing literature. First, it provides more complete understanding of a firm's desorptive capacity and the latter's effect on the supply chain context. The explanatory power of desorptive capacity clarifies how firms enhance their supply chain competence by identifying knowledge transfer opportunities and facilitating application of knowledge at recipient suppliers. Although research has focused on analyzing the recipient's absorptive capacity in a context of knowledge transfer, desorptive capacity has received limited attention, as studies like Ritala et al. (2015) show. We contribute to the research stream by investigating the effects of desorptive capacity on the organization's competence to manage its supply chain. By demonstrating operational benefits for the source firm to transfer knowledge to its supply network, this paper also reinforces the collaborative dimension in knowledge transfer (Schulze et al., 2014).

Second, we are among the first to investigate the moderating role of combinedand balanced ambidexterity in a single study. Identifying both moderating variables that enhance the influence of an organization's desorptive capacity on its competence to manage its supply chain constitutes a research contribution, since the literature has focused largely on one dimension of ambidexterity or the other. The need to analyze both aspects in a single study to deepen understanding of ambidexterity has been recognized by Birkinshaw (2004), He and Wong (2004), Lubatkin et al. (2006), and Gibson and Junni et al. (2013), among others; and Cao et al. (2009) have performed such an analysis. Our study's conceptual and empirical clarification of organizational ambidexterity and that of the abovementioned study enable comparison and should be addressed by other researchers in the field. We thus contribute to future theorization of 
conceptualization and measurement of organizational ambidexterity. Furthermore, we add to the existing debate in the literature regarding the feasibility of simultaneously pursuing exploration and exploitation activities in an organization.

Third, like the study by Blome et al. (2013), ours contributes to clarifying the role of organizational ambidexterity in its two distinct dimensions in a supply chain environment, a stream of research that needs further attention. Taken together, our findings highlight the challenges associated with applying organizational theory to the supply chain environment.

\subsection{Practical implications}

Our study also has important implications for managers. First, as to the significant effects of desorptive capacity, firms should continue to develop their own desorptive capacity so that this capacity can benefit the entire supply chain. On the one hand, firms must develop their ability to identify knowledge transfer opportunities and to support this process to maximize and protect the value of their knowledge. On the other, if firms pay less attention to developing and maintaining their unique capability, they risk losing their potential value in the supply chain in the long term.

Second, managers should be aware that the benefits from their organization's teaching activities depend on how they handle simultaneous pursuit of exploration and exploitation activities. Our findings indicate that an organization's desorptive capacity is supported by the two distinct dimensions of organizational ambidexterity to gain competitiveness at supply chain level. These findings have practical implications for management because prior research has not clarified whether managers should concern themselves more with achieving a balance between exploration and exploitation or attempting to achieve high levels of both simultaneously. The effort of balancing and 
combining high degrees of exploration and exploitation allows firms to leverage the benefits of desorptive capacity in the supply chain context. As Patel et al. (2012) acknowledge, managers should seek to improve quality, cost, and reliability while recognizing the importance of promoting outside-the-box thinking in the organization and the supply chain to which they belong and exploring new technologies, processes, and products.

\subsection{Research limitations and future research directions}

This study is not exempt from limitations, which must be taken into account when interpreting the results. The first limitation is the use of self-reported and singlerespondent data. A single informant per organization participated in the survey and answered all questions for this research. Our methodology section (robustness analysis) suggests that this measure does not invalidate our results. Second, this study uses crosssectional data, but an organization's desorptive capacity and ambidexterity can evolve over time. It is thus advisable to perform a longitudinal study to follow the evolution of desorptive capacity and organizational ambidexterity over time to demonstrate the pathdependent role of dynamic capabilities.

Additionally, further research should be done to investigate the influence of desorptive capacity on an organization's performance and the possible factors that enhance or undermine this relationship. Future research could explore the antecedents that foster desorptive capacity. Additionally, qualitative research could provide knowledge on how to implement desorptive capacity in supply chain management. These efforts can be complemented with secondary rather than perceptual data to improve the quality of future results. 


\section{References}

Andriopoulos, C. and Lewis, M.W. (2009), "Exploitation-exploration tensions and organizational ambidexterity: Managing paradoxes of innovation", Organization Science, Vol. 20, pp. 696-717.

Armstrong, J.S. and Overton, T.S. (1977), "Estimating nonresponse bias in mail surveys", Journal of Marketing Research, Vol. 14 No. 3, pp. 396-402.

Arora, A., Fosfuri, A. and Gambardella, A. (2001), "Markets for technology and their implications for corporate strategy", Industrial and Corporate Change, Vol.10 No. 2, pp. 419-451.

Azadegan, A. and Dooley, K.J. (2010), "Supplier innovativeness, organizational learning styles and manufacturer performance: An empirical assessment", Journal of Operations Management, Vol. 28 No. 6, pp. 488-505.

Birkinshaw, J. and Gibson, C. (2004), "Building ambidexterity into an organization", MIT Sloan Management Review, Vol. 45 No. 4, pp. 47-55.

Birkinshaw, J. and Gupta, K. (2013), "Clarifying the distinctive contribution of ambidexterity to the field of organization studies", The Academy of Management Perspectives, Vol. 27 No. 4, pp. 287-298.

Blome, C., Schoenherr, T. and Kaesser, M. (2013), "Ambidextrous governance in supply chains: The impact on innovation and cost performance", Journal of Supply Chain Management, Vol. 49 No. 4, pp. 59-80.

Bowersox, D., Closs, D., Stank, T. and Keller, S. (2000), "How supply chain competency leads to business success", Supply Chain Management Review, Vol. 4 No. 4, pp. 70-78.

Cao, Q., Gedajlovic, E. and Zhang, H. (2009), "Unpacking organizational ambidexterity: Dimensions, contingencies and synergistic effects", Organization Science, Vol. 20, pp. 781-796.

Chen, M-J. (2002), "Transcending paradox: The Chinese "middle way" perspective", Asia Pacific Journal of Management, Vol. 19, pp. 179-199.

Chesbrough, H. (2006), Open Business Models: How to Thrive in the New Innovation Landscape, Harvard Business School Press, Boston, MA.

Chow, W.S., Madu, C.N., Kuei, C.H., Lu, M.H., Lin, C. and Tseng, H. (2008), "Supply chain management in the US and Taiwan: An empirical study", Omega, Vol. 36, pp. 665-679.

Dyer, J.H. and Singh, H. (1998), "The relational view: Cooperative strategy and sources of interorganizational competitive advantage", Academy of Management Review, Vol. 23 No. 4, pp. 660-679. 
Fisher, M., Raman A. and McClelland A.S. (2000), "Rocket science retailing is almost here, are you ready?", Harvard Business Review, Vol. 78 No. 4, pp. 115-124.

Flint, D.J., Larsson, E. and Gammelgaard, B. (2008), "Exploring processes for customer value insights, supply chain learning and innovation: An international study", Journal of Business Logistics, Vol. 29 No. 1, pp. 257-281.

Florén, H. and Frishammar, J. (2012), "From preliminary ideas to corroborated product definitions: Managing the front end of new product development", California Management Review, Vol. 54 No. 4, pp. 20-43.

Fornell, C. and Larcker, D.F. (1981), "Evaluating structural equation models with unobservable variables and measurement error", Journal of Marketing Research, Vol. 18 , pp. 39-50.

Gibson, C.A.B. and Birkinshaw, J. (2004), "The antecedents, consequences, and mediating role of organizational ambidexterity", Academy of Management Journal, Vol. 47, pp. 209-226.

Green, Jr., Kenneth, W., Anthony Inman, R., Birou, L.M. and Whitten, D. (2014), "Total JIT (TJIT) and its Impact on supply chain competency and organizational performance", International Journal of Production Economics, Vol. 147, pp. 125-135.

Grindley, P.C. and Teece, D.I. (1997), "Managing intellectual capital: Licensing and cross-licensing in semiconductors and electronics", California Management Review, Vol. 39 No. 2, pp. 8-41.

Gupta, A.K., Smith, K.G. and Shalley, C.E. (2006), "The interplay between exploration and exploitation”, Academy of Management Journal, Vol. 49 No. 4, pp. 693-706.

Hair, J., Tatham, R., Anderson, R. and Black, W. (2010), Multivariate Data Analysis, , Prentice-Hall, Upper Saddle River, NJ.

Hardy, C., Phillips, N. and Lawrence, T. (2003), "Resources, knowledge and influence: The organizational effects of interorganizational collaboration", Journal of Management Studies, Vol. 40 No. 2, pp. 321-347

He, Z. and Wong, P. (2004), "Exploration vs. exploitation: An empirical test of the ambidexterity hypothesis", Organization Science, Vol. 15, pp. 481-494.

Heide, M., Vaaland, T.I. and Grønhaug, K. (2008), "The paradoxical role of competence development in supply chain management: Empirical findings from Norway", International Journal of Logistics: Research \& Applications, Vol. 11 No. 1, pp. 1-15.

Hsu, C-C., Tan, C., Laosirihongthong, T. and Leong, G.K. (2011), "Entrepreneurial SCM competence and performance of manufacturing SMEs", International Journal of Production Research, Vol. 49 No. 22, pp. 6629-6649. 
Hu, Y., McNamara, P. and McLoughlin, D. (2015), "Outbound open innovation in biopharmaceutical out-licensing”, Technovation, Vol. 35 No. 1, pp. 46-58.

Jaccard, J., Wan, C.K. and Turrisi, R. (1990), "The detection and interpretation of interaction effects between continuous variables in multiple regression", Multivariate Behavioral Research, Vol. 25 No. 4, pp. 467-478.

Jia, F. and Lamming, R. (2013), "Cultural adaptation in Chinese-Western supply chain partnerships. Dyadic learning in an international context", International Journal of Operations \& Production Management, Vol. 33 No. 5, pp. 528-561.

Junni, P., Sarala, R. M., Taras, V. and Tarba, S.Y. (2013), "Organizational ambidexterity: A meta-analysis", Academy of Management Perspectives, Vol. 27 No. 4, pp. 299-312.

Kannan, V.R. and Tan, K.C. (2005), "JIT, TQM and SCM: Understanding their linkages and impact on business performance", Omega, Vol. 33, pp. 153-162.

Kuei, C.M.C., Chow, W.S. and Lu, M.H. (2005), "Supply chain quality and excellence in the new economy", Multinational Business Review, Vol. 31 No. 1, pp. 33-53.

Larsson, R., Bengtsson, L., Henriksson, K. and Sparks, J. (1998), "The interorganizational learning dilemma: Collective knowledge development in strategic alliances", Organization Science, Vol. 9, pp. 285-305.

Lawson, B. and Potter, A. (2012), "Determinants of knowledge transfer in inter-firm new product development projects", International Journal of Operations \& Production Management, Vol. 32 No. 10, pp. 1228-1247.

Levinthal, D.A. and March, J.G. (1993), "The myopia of learning", Strategic Management Journal, Vol. 14 No. 52, pp. 95-112.

Lichtenthaler, U. and Lichtenthaler, E. (2009), "A capability-based framework for open innovation: Complementing absorptive capacity", Journal of Management Studies, Vol. 46 No. 8, pp. 1315-1338.

Lichtenthaler, U. and Lichtenthaler, E. (2010), "Technology transfer across organizational boundaries: Absorptive capacity and desorptive capacity", California Management Review, Vol. 53 No. 1, pp. 154-170.

Liu, Y., Huang, Y., Luo, Y. and Zhao, Y. (2012), "How does justice matter in achieving buyer-supplier relationship performance?", Journal of Operations Management, Vol. 30 No. 5, pp. 355-367.

Lubatkin, M.H., Simsek, Z., Ling, Y. and Veiga, J.F. (2006), “Ambidexterity and performance in small-to medium-sized firms: The pivotal role of top management team behavioral integration", Journal of Management, Vol. 32 No. 5, pp. 646-672.

Madhok, A. and Tallman, S.B. (1998), "Resources, transactions and rents: Managing value through interfirm collaborative relationships", Organization Science, Vol. 9 No. 3, 
pp. 326-339.

Malhotra, A., Gosain, S. and El Sawy, O.A. (2005), "Absorptive capacity configurations in supply chains: Gearing for partner-enabled market knowledge creation", MIS Quarterly, Vol. 29 No. 1, pp.145-187.

March, J.G. (1991), "Exploration and exploitation in organizational learning", Organization Science, Vol. 2 No. 1, pp. 71-87.

Martín-de Castro, G. (2015), "Knowledge management and innovation in knowledgebased and high-tech industrial markets: The role of openness and absorptive capacity", Industrial Marketing Management, Vol. 47, pp. 143-146.

Meinlschmidt, J., Foerstl, K. and Kirchoff, H.F. (2016), "The role of absorptive and desorptive capacity in sustainable supply management", International Journal of Physical Distribution \& Logistics Management, Vol. 26 No. 2, pp. 117-211.

Mu, J., Tang, F. and Maclachlan, D.L. (2010), "Absorptive and disseminative capacity: Knowledge transfer in intra-organization network", Expert Systems with Applications, Vol. 37, pp. 31-38.

Müller-Seitz, G. (2012), "Absorptive and desorptive capacity-related practices at the network level - the case of SEMATECH", $R \& D$ Management, Vol. 42 No. 1, pp. 90-99.

Najafi Tavani, S., Sharifi, H., Soleimanof, S. and Najmi, M. (2013), “An empirical study of firm's absorptive capacity dimensions, supplier involvement and new product development performance", International Journal of Production Research, Vol. 51 No. 11, pp. 3385-3403.

Narasimhan, R. and Narayanan, S. (2013), "Perspectives on supply network-enabled innovations", Journal of Supply Chain Management, Vol. 49 No. 4, pp. 27-42.

O’Reilly, C.A. and Tushman, M.L. (2013), "Organizational ambidexterity: Past, present, and future", The Academy of Management Perspectives, Vol. 27 No. 4, pp. 324-338.

Patel, P.C., Terjsen, S. and Li, D. (2012), "Enhancing effects of manufacturing flexibility through operational absorptive capacity and operational ambidexterity", Journal of Operations Management, Vol. 30, pp. 201-220

Paulraj, A., Lado, A.A. and Chen, I.J. (2008), "Inter-organizational communication as a relational competency: Antecedents and performance outcomes in collaborative buyersupplier relationships", Journal of Operations Management, Vol. 26 No. 1, pp. 45-64.

Podsakoff, P.M., MacKenzie, S.B., Lee, J-Y. and Podsakoff, N.P. (2003), "Common method biases in behavioral research: A critical review of the literature and recommended remedies", Journal of Applied Psychology, Vol. 88, pp. 879-903. 
Ritala, P., Olander, H., Michailova, S. and Husted, K. (2015), "Knowledge sharing, knowledge leaking and relative innovation performance: An empirical study", Technovation, Vol. 35, pp. 22-31.

Roldán Bravo, M.I., Ruiz Moreno, A. and Lloréns Montes, F.J. (2016), “Supply network-enabled innovations: An analysis based on dependence and complementarity of capabilities", Supply Chain Management: An International Journal, Vol. 21 No. 5, pp. 642-660.

Rothaermel, F.T. and Alexandre, M.T. (2009), "Ambidexterity in technology sourcing: The moderating role of absorptive capacity", Organization Science, Vol. 20, pp. 759780 .

Ryo, S.Y. and Kim, K.K. (2015), "The impact of knowledge complementarities on supply chain performance through knowledge exchange", Expert Systems with Applications, Vol. 42, pp. 3029-3040.

Scherrer-Rathje, M., Deflorin, P. and Anand, G. (2014), "Manufacturing flexibility through outsourcing: effects of contingencies", International Journal of Operations \& Production Management, Vol. 34 No. 9, pp. 1210-1242.

Schulze, A., Brojerdi, G. and Von Krogh, G. (2014), "Those who know, do. Those who understand, teach: Disseminative capability and knowledge transfer in the automotive industry", Journal of Product Innovation Management, Vol. 31 No. 1, pp. 79-97.

Simonin, B. (1997), "The importance of collaborative know-how: An empirical test of the learning organization”, Academy of Management Journal, Vol. 40, pp. 1150-1174.

Simsek, Z., Heavey, C., Veiga, J.F. and Souder, D. (2009), "A typology for aligning organizational ambidexterity's conceptualizations, antecedents, and outcomes", Journal of Management Studies, Vol. 46, pp. 864-894.

Smith W.K. and Lewis M.W. (2011), "Toward a theory of paradox: A dynamic equilibrium model of organizing", Academy of Management Review, Vol. 36, pp. 381403.

Spekman R.E., Spear J. and Kamauff, J. (2002), "Supply chain competency: Learning as a key component", Supply Chain Management, Vol. 7 No. 1, pp. 41-55.

Tamayo Torres, J., Ruiz, A. and Lloréns, F.J. (2011), “The influence of manufacturing flexibility on the interplay between exploration and exploitation: The effects of organizational learning and the environment", International Journal of Production Research, Vol. 49 No. 20, pp. 6175-6198.

Tamayo Torres, J., Barrales Molina, V. and Pérez Arostegui, M.N. (2014), "The influence of manufacturing flexibility on strategic behaviours: A study based in Certified Quality Management Systems", International Journal of Operations \& Production Management, Vol. 34 No. 8, pp. 1028-1054. 
Tang, F., Mu, J. and MacLachlan, D.L. (2010), "Disseminative capacity, organizational structure and knowledge transfer", Expert Systems with Applications, Vol. 37 No. 2, pp. 1586-1593.

Teece, D.J. (1986), "Profiting from technological innovation: Implications for integration, collaboration, licensing and public policy", Research Policy, Vol. 15, pp. 285-305.

Teece, D.J. (2007), "Explicating dynamic capabilities: The nature and microfoundations of (sustainable) enterprise performance", Strategic Management Journal, Vol. 28 No. 13, pp. 1319-1350.

Tranekjer, T.L. and Knudsen, M.P. (2012), "The (unknown) providers to other firms' new product development: What's in it for them?", Journal of Product Innovation Management, Vol. 29 No. 6, pp. 986-999.

Tushman, M.L. and O'Reilly, C.A. (1996), “The ambidextrous organization: Managing evolutionary and revolutionary change", California Management Review, Vol. 38, pp. $1-23$.

Vanhaverbeke, W., Cloodt, M. and Van de Vrande, V. (2007), "Connecting absorptive capacity and open innovation", in Proceedings of the CAS Workshop on Innovation in CAS Centre for Advanced Study, pp. 1-22.

Wagner, S.M. (2012), "Tapping supplier innovation", Journal of Supply Chain Management, Vol. 48 No. 2, pp. 37-52.

Wei, Z., Yi, Y. and Guo, H. (2014), "Organizational learning ambidexterity, strategic flexibility, and new product development", Journal of Product Innovation Management, Vol. 31 No. 4, pp. 832-847.

Winter, S.G. (1987), "Knowledge and competence as strategic assets". in D.A. Klein (Ed.), The competitive challenge strategies for industrial innovation and renewal, Elsevier, Woburn, MA.

Wu, I.L., Chuang, C.H. and Hsu, C.H. (2014), "Information sharing and collaborative behaviors in enabling supply chain performance: A social exchange perspective", International Journal of Production Economics, Vol. 148, pp. 122-132.

Yang, S.-M., Fang, S.-C., Fang, S.-R. and Chou, C.-H. (2014), "Knowledge exchange and knowledge protection in interorganizational learning: The ambidexterity perspective", Special Issue on Co-opetition Cooperation and Competition, Vol. 43 No. 2, pp. 346-358.

Ziegler, N., Ruether, F., Bader, M. and Gassmann, O. (2013), "Creating value through external intellectual property commercialization: A desorptive capacity view", Journal of Technology Transfer, Vol. 38, pp. 930-949. 
TABLE I

\begin{tabular}{|ccc|}
\hline \multicolumn{3}{|c|}{ Demographic } \\
\hline Characteristics & Frequency & Percent \\
\hline Industry type & & \\
\hline High-tech Manufacturing & 79 & $29.26 \%$ \\
Traditional Manufacturing & 100 & $37.04 \%$ \\
Services & 91 & $33.7 \%$ \\
\hline Annual revenue & & \\
\hline$<1000 \mathrm{M}$ & 0 & 0 \\
$1000-10,000 \mathrm{M}$ & 83 & $30.74 \%$ \\
$10,000-100,000 \mathrm{M}$ & 158 & $58.52 \%$ \\
$>100,000 \mathrm{M}$ & 29 & $10.74 \%$ \\
\hline Number of employees & & \\
\hline $0-49$ & 13 & $4.82 \%$ \\
$50-250$ & 202 & $74.81 \%$ \\
$>250$ & 55 & $20.37 \%$ \\
\hline
\end{tabular}

TABLE II

\begin{tabular}{|c|c|c|c|c|c|c|c|c|c|}
\hline \multicolumn{10}{|c|}{ Mean, standard deviation, and correlations } \\
\hline Factors & Mean & S.D. & 1 & 2 & 3 & 4 & 5 & 6 & 7 \\
\hline 1.Desorptive Capacity (DC) & 5.21 & 1.06 & 0.89 & & & & & & \\
\hline 2. Supply Chain Competence (SCC) & 5.85 & 0.74 & $0.57^{* * *}$ & 0.76 & & & & & \\
\hline 3. Balanced Di of ambidex (BA) & 5.99 & 0.98 & -0.04 & -0.10 & & & & & \\
\hline 4. Combined Di of ambidex (CA) & 0.40 & 1.48 & -0.09 & $-0.16^{* * *}$ & $0.39^{* * *}$ & & & & \\
\hline 5. Exploration (EXPLOR) & 5.27 & 1.09 & $0.47^{\star \star *}$ & $0.45^{* * *}$ & $-0.16^{\star * *}$ & $-0.34^{* \star *}$ & 0.74 & & \\
\hline 6. Exploitation (EXPLOIT) & 4.79 & 1.17 & $0.23^{\star \star *}$ & $0.24^{* * *}$ & $0.59^{* \star *}$ & -0.02 & $0.32^{\star \star \star}$ & 0.82 & \\
\hline 7. Firm Size (FS) & 4.97 & 0.86 & -0.11 & $-0.15^{\star *}$ & 0.06 & 0.09 & $-0.13^{\star *}$ & -0.1 & \\
\hline 8. Sector (S) & 0.71 & 0.46 & -0.01 & 0.03 & -0.07 & -0.03 & 0.07 & 0.02 & $-0.22^{* * *}$ \\
\hline
\end{tabular}


TABLE III

\begin{tabular}{|c|c|c|c|c|}
\hline \multicolumn{5}{|c|}{ Results of OLS regression analysis } \\
\hline & \multicolumn{4}{|c|}{ Determinants of supply chain competence } \\
\hline & Model 1 & Model 2 & Model 3 & Model 4 \\
\hline \multicolumn{5}{|l|}{ Control variables } \\
\hline Employees & -0.089 & -0.076 & -0.052 & -0.047 \\
\hline Sector & -0.021 & -0.031 & -0.003 & -0.001 \\
\hline Exploration & $0.411^{\star * \star}$ & $0.347^{\star \star \star}$ & $0.155^{\star *}$ & $0.159^{* *}$ \\
\hline Exploitation & $0.102^{*}$ & $0.251^{\star \star \star}$ & $0.186^{\star \star}$ & 0.112 \\
\hline \multicolumn{5}{|l|}{ Main effect } \\
\hline Balanced ambidexterity (BA) & & $-0.211^{\star \star}$ & $-0.17^{* *}$ & $-0.161^{\star \star}$ \\
\hline Combined ambidexterity (CA) & & 0.046 & 0.006 & -0.011 \\
\hline Desorptive Capacity (DC) & & & $0.445^{\star \star *}$ & $0.436^{\star * *}$ \\
\hline \multicolumn{5}{|l|}{ Moderating effects } \\
\hline DC $x$ BA & & & & $0.1^{*}$ \\
\hline $\mathrm{DC} \times \mathrm{CA}$ & & & & $0.13^{\star \star}$ \\
\hline $\mathrm{R}^{2}$ & 0.223 & 0.242 & 0.393 & 0.42 \\
\hline Adjusted $\mathrm{R}^{2}$ & 0.211 & 0.224 & 0.377 & 0.4 \\
\hline Model F & $19.011^{* * *}$ & $13.976^{\star * *}$ & $24.256^{\star * *}$ & $20.951^{\star * *}$ \\
\hline
\end{tabular}

Figure 1

Summary of Hypotheses

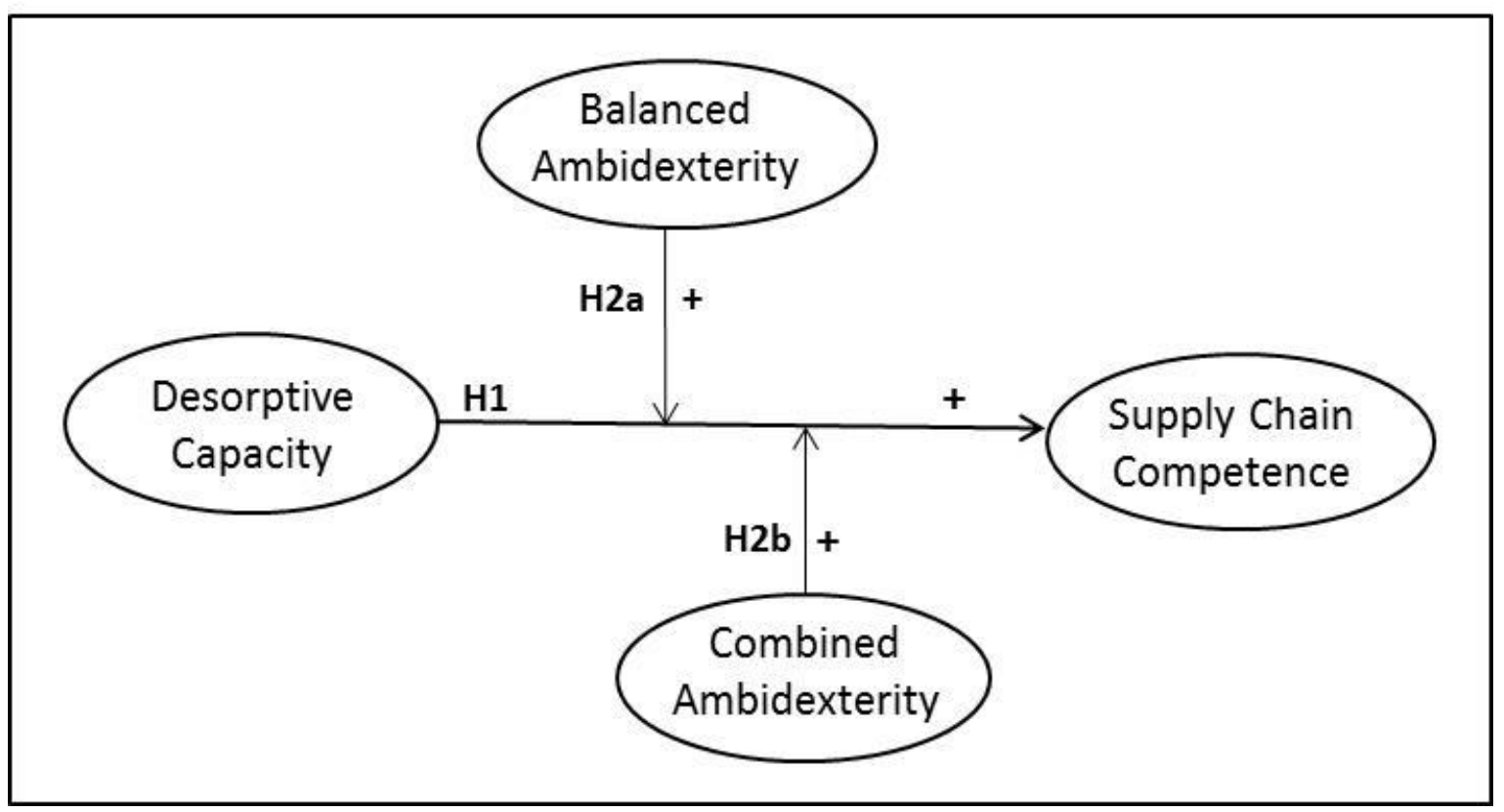

